\title{
Volatile and odoriferous compounds changes during frozen concentrated orange juice processing
}

\author{
Raíssa Bittar Mastello a, Natália Soares Janzantti ${ }^{\mathrm{b}}$, Magali Monteiro a,* \\ a Department of Food and Nutrition, School of Pharmaceutical Sciences, São Paulo State University-UNESP, 14801-902 Araraquara, SP, Brazil \\ ${ }^{\mathrm{b}}$ Department of Food Engineering and Technology, IBILCE, São Paulo State University-UNESP, 15054-000 São José do Rio Preto, SP, Brazil
}

\section{A R T I C L E I N F O}

\section{Article history:}

Received 26 June 2015

Received in revised form 28 September 2015

Accepted 3 October 2015

Available online 9 October 2015

\section{Keywords:}

HS-SPME-GC-MS

GC-olfactometry

Orange juice

FCOJ processing steps

Volatile compounds

\begin{abstract}
A B S T R A C T
Sixty-two volatile compounds were identified in orange juice from frozen concentrated orange juice (FCOJ) processing steps using HSSPME-GC-MS in combination with GC-OSME. Twenty-four compounds were perceived by OSME in the juice from the extraction step, twenty-five from the finishing step, nineteen from the $1^{\text {st }}$ stage of evaporator step, nine from the concentration step and fourteen from the blending step. Ethyl butanoate, D-limonene, nonanal, ethyl octanoate and decanal showed major odoriferous importance for the juice from the extraction step. They were also considered to be of major odoriferous importance in the finishing step, apart from nonanal and ethyl octanoate. D-Limonene showed the highest odoriferous intensity in all the steps and it was the only major compound in the $1^{\text {st }}$ stage of evaporator, concentration and blending steps.

The majority of compounds showed a decrease in odour intensity during the processing. Principal component analysis showed that syrup, fruity, green, lavender, citrus and green leaf descriptors were reduced during the processing, from the extraction and finishing steps up to the $1^{\text {st }}$ stage of evaporator step, while stink bug increased. Gas and green leaf descriptors were more important to the aroma of the juice from the $1^{\text {st }}$ stage of evaporator, concentration and blending steps, and eucalyptus and plastic to the juice from the extraction and finishing steps. Ten volatile compounds were quantified by HS-SPME-GC-MS. Ethyl butanoate concentration was higher in the finishing step, being strongly reduced in the $1^{\text {st }}$ stage of evaporator step, and $\beta$-pinene, myrcene and longifolene were higher in the extraction step. 1-Octanol, linalool, $\alpha$-terpineol, $\beta$-citronellol, perillaldehyde and decanal were higher in the finishing step. All of them showed a decrease in concentration from the extraction and finishing step up to the end of the FCOJ processing, affecting the final product aroma quality.
\end{abstract}

(c) 2015 Elsevier Ltd. All rights reserved.

\section{Introduction}

Orange juice is an important traded commodity lead by Brazil and USA. Frozen concentrated orange juice (FCOJ) is the main product, which processing has been applied for more than 50 years. FCOJ processing is considered the most profitable and well-established for orange juice production, making the final product readily storable because of its reduced volume and easy-to-ship characteristics. This thermal processing aims to inactivate the heat-stable pectinmethylesterase (PME) and eliminate spoilage microorganisms, extending the juice shelf life. Depending on the processing conditions of temperature and time, orange juice aroma and flavour can be affected, therefore reducing the overall acceptance (Janzantti, Machado, \& Monteiro, 2011).

FCOJ is mostly consumed, having a valuable position in the market, what makes important to identify the volatile compounds, their impact on the aroma and flavour of the juice, as well as by-products from process induced reactions (e.g. Strecker degradation, lipid oxidation) (Vervoort et al., 2012). Orange juice volatile compounds have been

\footnotetext{
* Corresponding author.

E-mail address: monteiro@fcfar.unesp.br (M. Monteiro).
}

extensively investigated. Steffen and Pawliszyn (1996) proposed a method for the extraction and quantification of seventeen volatile compounds of commercial orange juice by HS-SPME and GC-FID, including methanol, ethanol, ethyl acetate, 2-methyl-1-propanol, methyl butanoate, ethyl butanoate, cis-3-hexen-1-ol, hexyl alcohol, $\alpha$-pinene, $\beta$ myrcene, ethyl hexanoate, octanal, limonene, $\gamma$-terpinene, linalool, $\alpha$ terpineol and decanal, which was considered effective for flavour volatiles. Shaw, Buslig, and Moshonas (1993) classified freshly-squeezed, pasteurised and two types of reconstituted from concentrated orange juices by pattern recognition techniques analysing nineteen volatile compounds by GC-FID. A good separation was obtained among the volatile compounds from different types of orange juice and that aseptically packaged reconstituted juice from concentrate, the one with a unique volatile compound profile. Jordán, Goodner, and Laencina (2003) studied the effect of deaeration and pasteurisation on the volatile profile of fresh orange juice by GC-FID and GC-MS, showing that significant losses occurred during the deaeration process, and pasteurisation did not modify the volatile profile of the already deaerated orange juice. However there have been few attempts to identify and quantify the odour-active compounds. Tønder, Petersen, Poll, and Olsen (1998) used aroma value calculation and GC odour profiling to compare the aroma of freshly 
made and stored reconstituted orange juice. Both parameters were useful to discriminate the juices and showed ethyl butanoate, limonene, octanal and linalool as important contributors to orange juice aroma. Rouseff, Bazemore, Goodner, and Naim (2001) used SPME and GC-OSME to analyse unheated orange juice (freshly-squeezed) and heated orange juice (pasteurised in the laboratory), showing that there were eighteen volatile compounds common to both samples, with different intensities. Six aroma peaks were lost due to heating and five new peaks were formed as a result of heating. Arena, Guarrera, Campisi, and Nicolosiasmundo (2006) compared the aroma profile of hand-squeezed juices from different orange varieties using GC-O detection frequency method. Twentytwo odour active compounds were detected. Limonene was predominant in all the orange juices. The aroma profiles of the blond juices were very different when compared to the blood varieties, which had higher total odour intensity and were mostly characterised by methyl butanoate. Elston, Sims, Mahattanatawee, and Rouseff (2006) employed a sensorydriven multivariate technique to evaluate thirteen commercial samples and associate the descriptors with flavour quality. The juices could be divided into three groups based on quality scores, and the most discriminating odour active compounds were octanal, ethyl butanoate/hexanal, 4mercapto-4-methyl-2-pentanone, furaneol, 4-vinylguaiacol, $p$-methen8-thiol, 2-methyl-3-furanthiol, vanillin, methional, (E)-2-nonenal and 4mercapto-4-methyl-2-pentanol. Obenland et al. (2008) studied commercial packing and storage of navel oranges for changes in aroma-active volatiles using a GC-O time-intensity technique, showing that ethyl butanoate, ethyl hexanoate and four non-identified volatile compounds increased in the packed fruit, while limonene decreased. To the best of our knowledge there are no studies focusing on the steps of the FCOJ processing, especially the volatile compounds identification and quantification, in order to understand what happens with the juice during the processing and establish an aroma fingerprint for each step.

Because the volatile compounds profile from GC-FID or GC-MS may not reveal the actual aroma of the sample, as different compounds have various odour thresholds and area does not always reflect its odour activity, GC-O is the choice to characterise the aroma. Brunschwig et al. (2012) compared CHARM with OSME analysis for the identification of odour-active compounds of Tahitian vanilla flavour. The OSME analysis enabled the detection of a higher number of odourant zones, and it was selected for further assessment of the diversity among the three cultivars analysed. GC-O (OSME), a time-intensity technique, is the most used to assess the intensity of an odour-active compound by using the human nose as detector and a scale to rate the intensities.

The novelty of this study relies on the integrated approach where HS-SPME-GC-MS was used in combination with GC-OSME to study the odour-active compounds of orange juice. The aim of the work was to study the aroma of orange juice in order to uncover changes during the FCOJ processing. Also the relationships between juice and processing steps were investigated to determine which aroma descriptors characterise the juice from each step and how they behave up to the end of FCOJ processing.

\section{Material and methods}

\subsection{Orange juice}

Orange juice from Pêra-Rio variety in the 2012 harvest of the FCOJ processing steps was supplied by a citrus industry, Araraquara, SP, Brazil. Juice from the extraction $\left(11.5^{\circ} \mathrm{Brix}\right)(3 \mathrm{~L})$, finishing $\left(11.8^{\circ} \mathrm{Brix}\right)$ $(3 \mathrm{~L}), 1^{\text {st }}$ stage of evaporator $(3 \mathrm{~L})$, concentration $(1 \mathrm{~kg})$ and blending (1 kg) steps were used. The collection of the juice from each step was performed from the same load of oranges, so that all the juice collected was from the same FCOJ processing batch. After collection the juice was packaged in high density polyethylene bottles $(500 \mathrm{~mL})$, transferred to the laboratory and then packaged in amber glass bottles $(30 \mathrm{~mL})$, and frozen until analysed. The juice from the $1^{\text {st }}$ stage of evaporator, concentration and blending steps was reconstituted with water up to $11.8^{\circ}$ Brix prior the analysis.

The FCOJ processing consists of a series of operations. After arriving the industry fruits are selected, washed and directed to the extraction. Then the juice follows to finisher to remove pulp and vesicles. After finishing, juice is submitted to concentration, in order to evaporate water up to $66^{\circ}$ Brix and guarantee enzymatic and microbiological stability. The concentrated orange juice is then cooled down in flash coolers. In the next operation oil phase is added in the juice partially replacing the volatile compounds lost in concentration (Nagy \& Chen, 1993). In this work, the extraction was performed in a FMC Citrus Juice Extractor, the most used in the Brazilian citrus plants (extraction step). Then juice followed to the finisher (finishing step). The concentration was performed in a multiple-effect evaporator TASTE (Thermally Accelerated Short Time Evaporator) and juice was collected after the $1^{\text {st }}$ stage of evaporator ( $1^{\text {st }}$ stage of evaporator step). From the last evaporator stage the concentrated juice was pumped through the flash cooler (concentration step). After concentration and cooling juice was blended just with oil phase (blending step).

\subsection{HS-SPME sampling}

The headspace solid phase microextraction (HS-SPME) was performed using a manual holder with a $10 \mathrm{~mm}$ length $50 / 30 \mu \mathrm{m}$ fibre (Supelco, Bellefonte, PA, USA). The influence of exposure time and temperature on the volatile compounds profile and area of peaks was previously evaluated using response surface methodology, in order to choose the HS-SPME conditions for the analysis of orange juice (results not shown). The PDMS/CAR/DVB fibre was chosen because of its large polarity range, which allowed wider profile and aroma representativeness. $10 \mathrm{~mL}$ of juice was transferred to a $20 \mathrm{~mL}$ vial sealed with PTFEsilicone septa (Supelco, Bellefonte, PA, USA), containing a magnetic stirring bar $(8 \mathrm{~mm})$. After a $17 \mathrm{~min}$ equilibration time at $37 \pm 1{ }^{\circ} \mathrm{C}$ the fibre was exposed to the sample headspace for 25 min under stirring (31.42 $\mathrm{rad} \mathrm{s}^{-1}$ ). The fibre was previously conditioned following the manufacturer's instructions (Mastello, Capobiango, Chin, Monteiro, \& Marriott, 2015).

\subsection{GC-FID analysis}

A Shimadzu GC-17A (Kyoto, Japan) with a flame ionization detector (FID) was used. The GC inlet and detector temperatures were $250{ }^{\circ} \mathrm{C}$, and the fibre was exposed in the inlet for $2 \mathrm{~min}$ in splitless mode. The hydrogen carrier flow rate was $1.7 \mathrm{~mL} \mathrm{~min}{ }^{-1}$. The column used was HP-5 MS column $(30 \mathrm{~m} \times 0.25 \mathrm{~mm} \times 0.25 \mu \mathrm{m})$ (Agilent, Santa Clara, CA, USA), initially programmed at $40^{\circ} \mathrm{C}$ for $3 \mathrm{~min}$, ramp of $3{ }^{\circ} \mathrm{C} \mathrm{min}-1$ up to $160{ }^{\circ} \mathrm{C}$; and then $10^{\circ} \mathrm{C}$ min $^{-1}$ up to $230{ }^{\circ} \mathrm{C}$ for $10 \mathrm{~min}$. A series of alkanes $\left(\mathrm{C}_{8}-\mathrm{C}_{20}\right)$ was employed to establish the retention indices in the HP-5MS column (van Den Dool \& Kratz, 1963), that was also compared with those from the GC-MS.

\subsection{Gas chromatography-mass spectrometry (GC-MS)}

GC-MS analysis was performed using an Agilent 7890A gas chromatograph coupled with a $5975 \mathrm{C}$ single-quadrupole mass spectrometer. The capillary column was a HP-5MS (30 $\mathrm{m} \times 0.25 \mathrm{~mm} \times 0.25 \mu \mathrm{m})$ (Agilent, Santa Clara, CA, USA), programmed at $40{ }^{\circ} \mathrm{C}$ for $3 \mathrm{~min}$, with ramp of $3^{\circ} \mathrm{C} \mathrm{min}-1$ up to $160^{\circ} \mathrm{C}$; and then $10^{\circ} \mathrm{C} \mathrm{min}^{-1}$ up to $230{ }^{\circ} \mathrm{C}$, and hold for $10 \mathrm{~min}$. The GC inlet was set at $250{ }^{\circ} \mathrm{C}$ with splitless sampling time of $2 \mathrm{~min}$. The helium carrier flow rate was $1.7 \mathrm{~mL} \mathrm{~min}{ }^{-1}$. The DB-Wax column $(30 \mathrm{~m} \times 0.25 \mathrm{~mm} \times 0.25 \mu \mathrm{m})(\mathrm{J} \& \mathrm{~W}$, Folsom, CA, USA) was programmed at $40{ }^{\circ} \mathrm{C}$ for $5 \mathrm{~min}$, with ramp of $3{ }^{\circ} \mathrm{C} \mathrm{min}{ }^{-1}$ up to $200^{\circ} \mathrm{C}$ for $10 \mathrm{~min}$, with a helium carrier flow rate of $1.0 \mathrm{~mL} \mathrm{~min}{ }^{-1}$.

Transfer line temperature was maintained at $280^{\circ} \mathrm{C}$. The quadrupole mass spectrometer was operated in the electron impact mode and the 
source temperature was $230{ }^{\circ} \mathrm{C}$. All analyses were performed setting ionisation energy at $70 \mathrm{eV}$ and electron multiplier voltage at $1200 \mathrm{~V}$.

The identification of the compounds was based on their mass spectra compared to the NIST library (v. 2.0) and pure standards in the HP-5MS and DB-Wax columns. When the pure standards were not available the compound was considered tentatively identified. A series of alkanes $\left(C_{8}-C_{20}\right)$ was employed to establish the retention indices in the two columns (van Den Dool \& Kratz, 1963), that was also compared with those of the literature (Acree \& Arn, 2015; Mastello et al., 2015) and of pure standards.

Initially, full scan data with a mass/charge range of 35-350 amu at a rate of $1.71 \mathrm{scan} / \mathrm{s}$ were acquired to determine appropriate $\mathrm{m} / \mathrm{z}$ for the later acquisition and quantification. Quantification was performed in selected ion monitoring. The internal standard calibration was used, with the juice from the extraction step was as matrix, because of its representativeness of orange juice aroma. Calibration curves for each compound were plotted using isopentyl acetate as the internal standard. $100 \mu \mathrm{L}$ of an internal standard solution $(3 \mu \mathrm{g} / \mathrm{mL})$ was added to $10 \mathrm{~mL}$ of orange juice. The juice from each step of the FCOJ processing was analysed in triplicate using HS-SPME followed by GC-MS.

\subsection{Gas chromatography-olfactometry (GC-O)}

The GC-O analysis was performed in a Shimadzu GC-2010 equipped with a SGE olfactory port (ODO II model, Texas, USA) using the OSME technique. The SCDTI (time-intensity data collection system) data collection program was used (Da Silva, Lundhal, \& McDaniel, 1994). The panellists were requested to record the intensity of each odour using a 10 -point hybrid scale anchored with the terms "none", "moderate" and "strong" in the points 0,5 and 10, respectively, and also were asked to describe the odour perceived. Three panellists, one male and two female, aged between 25 and 35 years old, were trained and selected by odour recognition. Freshly-squeezed and overripe orange juice and essences of anise, guarana syrup, camomile, grass, strawberry, eucalyptus and green papaya fruit were presented to the panellists in $300 \mathrm{~mL}$ black mugs covered with aluminium paper with holes and a watch glass. They were asked to describe the odour after sniffing the mugs, and were selected if capable to describe at least $70 \%$ of the odours (ASTM - American Society for Testing and Material, 1981). After selection the panellists were trained on the OSME technique to distinguish the odours characteristic of orange juice and get used to the software and scale.

The capillary column was DB-5 ( $30 \mathrm{~m} \times 0.25 \mathrm{~mm} \times 0.25 \mu \mathrm{m})(\mathrm{J} \& \mathrm{~W}$, Folsom, CA, USA). The GC inlet was set at $250{ }^{\circ} \mathrm{C}$ with splitless sampling time of $2 \mathrm{~min}$. The hydrogen carrier flow rate was $1.7 \mathrm{~mL} \mathrm{~min}^{-1}$. The temperature was programmed at $40{ }^{\circ} \mathrm{C}$ for $3 \mathrm{~min}$, ramp of $3{ }^{\circ} \mathrm{C} \mathrm{min}{ }^{-1}$ up to $160{ }^{\circ} \mathrm{C}$; and then $10{ }^{\circ} \mathrm{C} \mathrm{min}{ }^{-1}$ up to $230{ }^{\circ} \mathrm{C}$ for $10 \mathrm{~min}$. A deactivated fused silica transfer line was used to direct the effluent from the column to the olfactory port. The SGE ODO-II system was used to deliver the outlet gas to the olfactory port and to heat the transfer line. The olfactory port $\left(250^{\circ} \mathrm{C}\right)$ was supplied with a constant flow of $300 \mathrm{~mL} / \mathrm{min}$ of humidified air. The orange juice from each FCOJ processing step was analysed by each panellist in triplicate. Each GC-O analysis lasted $30 \mathrm{~min}$, corresponding to the total analysis time (60 min) divided into two sessions.

Individual aromagrams for each sample and panellist were constructed based on the data collected in SCDTI software (Janzantti, Macoris, Garruti, \& Monteiro, 2012). The odoriferous peaks should be detected in at least two of the three repetitions. Then, a consensual aromagram was constructed based on the individual aromagrams, using the same criteria aforementioned, that the peaks should be detected by at least two of the three panellists.

The description of each odour was established by gathering the description of all the panellists. The GC-FID chromatograms and the aromagrams were aligned by calculating the retention indices in both systems. Peak identification was related with the odour description by calculating the retention indices in the GC-MS. The odour descriptions were compared to that from the literature (Acree \& Arn, 2015; Mastello et al., 2015; Rouseff et al., 2001 and used as an additional parameter in the compounds' identification. The odoriferous compounds were represented by the same numbers of the peaks on the chromatogram. Letters were attributed to those compounds that were only perceived by GC-O.

\subsection{Statistical analysis}

The principal component analysis (PCA) was carried out using the aroma descriptors and the odoriferous intensity for the juice of each step of the FCOJ processing, in order to verify which aroma descriptors characterise the juice from each step and how they behave up to the end of the FCOJ processing. Groups were highlighted according to the location of the descriptors and steps of processing. One-way ANOVA and Tukey or Student t-tests $(p \leq 0.05)$ were used to compare means of the quantified volatile compounds. All the statistical analysis were performed using STATISTICA 8 8.0 Software.

\section{Results and discussion}

\subsection{Orange juice volatile compounds identification and GC-OSME}

Headspace solid phase microextraction (HS-SPME) was used to isolate the volatile compounds of orange juice from the FCOJ processing steps. GC-FID was used to analyse the volatile compounds profile of orange juice from each step and GC-MS to identify them and quantify as many compounds as possible. The OSME technique was used to assess the odoriferous importance of the volatile compounds of orange juice from the FCOJ processing steps. Table 1 shows the volatile compounds, retention indices (HP-5MS and DB-Wax columns), the aroma description and odoriferous intensity of orange juice from the steps of the FCOJ processing. Twenty-four compounds were perceived in the orange juice from the extraction step, twenty-five from the finishing step, nineteen from the $1^{\text {st }}$ stage of evaporator step, nine from the concentration step and fourteen from the blending step. Compounds with intensity of 5.0 or more were considered to be of major odoriferous importance, while those with intensity between 3.0 and 4.9 and between 0.1 and 2.9 were considered to be of moderate and weak odoriferous importance, respectively.

The volatile compounds of major odoriferous importance for the juice from the extraction step were ethyl butanoate, described as "syrup", D-limonene, described as "sweety, citrus", nonanal, described as "green, fruity", ethyl octanoate, described as "citrus, eucalyptus" and decanal, described as "citrus". These compounds, apart from nonanal and ethyl octanoate, were also considered to be of major odoriferous importance for the juice from the finishing step. D-Limonene is the compound with the highest odoriferous intensity in all the steps and the only major compound in the $1^{\text {st }}$ stage of evaporator, concentration and blending steps. The contribution of D-limonene for orange juice aroma is not clear, although it is one of the major compounds in orange juice. Perez-Cacho and Rouseff (2008) suggested that it might be possible that limonene is a "lifting agent" for other volatiles in a similar way as ethanol does in wine. Ethyl butanoate is the single most important ester and one of the most intense odourant in orange juice (Arena et al., 2006).

In Fig. 1 is presented the typical GC-FID chromatograms and aromagrams of orange juice from the beginning (extraction) and end (concentration) steps of the FCOJ processing. The blending step, in which oil phase is added to the juice, follows the concentration step. The majority of compounds showed a decrease in odour intensity during the FCOJ processing. Trans + cis- $\beta$-ocimene, described as "mint", terpinolene (mixture), described as "eucalyptus", linalool, described as "lavender", perillaldehyde, described as "tea, citrus, eucalyptus", and the non-identified compounds from peak 3 (RI 890), described as "sweety", and peak 42 (RI 1333), described as "stink bug", are considered to be of 
moderate odoriferous importance for the juice from the extraction step, decreased to the finishing step and then was not perceived up to the end of the processing, apart from perillaldehyde and the non-identified compound from peak 3 which odoriferous importance was maintained in the finishing step. Linalool is an important alcohol for the orange juice aroma, present in peel oil and with a distinctive floral aroma showed weak odoriferous importance in the $1^{\text {st }}$ stage of evaporator, concentration and blending steps. The non-identified compound from peak 42 maintained the odoriferous importance in the two first steps, decreased from the $1^{\text {st }}$ stage of evaporator step and was not perceived in the concentration step (Table 1 ).

Among the compounds with weak odoriferous importance in the juice from the extraction step, $\beta$-pinene, described as "green leaf", octanal, described as "eucalyptus", longifolene, described as "citrus", dodecanal + caryophyllene, described as "sweety, citrus", increased the odoriferous intensity in the finishing step and then were not perceived up to the end of the processing, while $\alpha$-terpineol, described as "citrus", and nerol $+\beta$-citronellol, described as "stink bug" maintained the odoriferous importance in the $1^{\text {st }}$ stage of evaporator and were not perceived in the concentration step. Cis-4-decenal, described as "eucalyptus", was not only perceived in the $1^{\text {st }}$ stage of evaporator step (Table 1 and Fig. 1). Because aldehydes are highly chemical reactive, their concentrations are easily altered after thermal processing. As confirmed in this study, aldehydes are known for having green notes (Perez-Cacho \& Rouseff, 2008).

Hexanal, described as "green leaf", $\beta$-myrcene, described as "plastic", terpinen-4-ol, described as "grease", 1-decanol, described as "ripen fruit", and a non-identified compound from peak 24 (RI 1148), described as "green leaf" showed an increase in odour intensity in the juice from the $1^{\text {st }}$ stage of evaporator step when compared to those from the extraction and finishing steps. Although hexanal naturally occurs in fruits and vegetables, and according to Shaw (1991) it is an important contributor to the aroma of orange juice, it was of weak odoriferous importance in the juice from extraction or finishing steps (Table 1 and Fig. 1).

Heptanal, described as "fatty" and the non-identified compounds A, B and C, described as "rotten", "gas,", and "plastic", respectively, were perceived by OSME only in the juice from $1^{\text {st }}$ stage of evaporator and concentration steps. The non-identified compounds A and B were considered to be of weak odoriferous importance in all the steps, while heptanal was of weak importance for the juice from the $1^{\text {st }}$ stage of evaporator step and moderate importance for the juice from the concentration and blending steps. Regarding the non-identified compound $\mathrm{C}$, it was considered to be of moderate and weak importance for the juice from the $1^{\text {st }}$ stage of evaporator and concentration steps, respectively (Table 1 and Fig. 1).

Some compounds were perceived only in a single step of the processing. Perillylalcohol, described as "citrus, eucalyptus" was perceived in the juice from the extraction step, linalyl acetate, described as "citrus" was perceived in the juice from the finishing step, $\rho$-mentha-1,3,8-triene and 1-octanol, described as "citrus" and "stink bug", respectively, were perceived in the juice from the $1^{\text {st }}$ stage of evaporator step. 1-octanol formation can be linked to unsaturated fatty acid degradation (Kebede et al., 2013), which might be induced by heating. In all these cases, the compounds were considered to be of weak importance for the juice, apart from 1-octanol and $\rho$-mentha-1,3,8-triene, which were considered to be of moderate odoriferous importance (Table 1 and Fig. 1).

Table 1

Volatile and odoriferous compounds of orange juice from the FCOJ processing steps.

\begin{tabular}{|c|c|c|c|c|c|c|c|c|c|}
\hline \multirow{2}{*}{ Peak $^{\mathrm{a}}$} & \multirow{2}{*}{$\mathrm{RI}^{\mathrm{b}}$} & \multirow{2}{*}{$\mathrm{RI}^{\mathrm{c}}$} & \multirow{2}{*}{ Compound } & \multirow{2}{*}{ Aroma description } & \multicolumn{5}{|l|}{$\mathrm{GC}-\mathrm{O}^{\mathrm{d}}$} \\
\hline & & & & & Extraction & Finishing & $1^{\text {st }}$ stage evaporator & Concentration & Blending \\
\hline A & $<800$ & - & ni & Rotten & - & - & 1.79 & 2.41 & 1.69 \\
\hline B & $<800$ & - & ni & Gas & - & - & 2.94 & 1.24 & 2.91 \\
\hline 1 & 800 & 1083 & Hexanal $^{\text {e,f,g }}$ & Green leaf & 2.90 & 2.66 & 3.72 & 3.64 & 3.17 \\
\hline 2 & 804 & 1038 & Ethyl butanoate $e^{\mathrm{e}, \mathrm{f}, \mathrm{g}}$ & Syrup & 5.54 & 5.61 & 2.25 & - & - \\
\hline 3 & 890 & - & ni & Sweety & 3.28 & 3.40 & - & - & - \\
\hline 4 & 903 & 1184 & Heptanal $^{\mathrm{f}, \mathrm{g}}$ & Fatty & - & - & 1.69 & 3.21 & 3.65 \\
\hline 5 & 931 & 1022 & $\alpha$-Pinene $e^{e, f, g}$ & $\mathrm{np}$ & - & - & - & - & - \\
\hline 6 & 972 & 1118 & $\beta$-Pinene $e^{e, f, g}$ & green leaf & 1.47 & 2.20 & - & - & - \\
\hline C & 985 & - & ni & Plastic & - & - & 3.73 & 0.92 & - \\
\hline 7 & 993 & 1167 & $\beta$-Myrcene $e^{e, f, g}$ & Plastic & 1.48 & - & 2.97 & - & 2.49 \\
\hline 8 & 1006 & 1288 & Octanal ${ }^{\mathrm{e}, \mathrm{f} g}$ & Eucalyptus & 2.64 & 3.64 & - & - & - \\
\hline 9 & 1023 & 1264 & Cymene $e^{\mathrm{f}, \mathrm{g}}$ & np & & & & & \\
\hline 10 & 1038 & 1200 & D-Limonene $e^{\mathrm{e}, \mathrm{f}, \mathrm{g}}$ & Sweety, citrus & 6.16 & 7.92 & 5.32 & 5.02 & 5.74 \\
\hline 11 & 1043 & 1251 & Trans- $\beta$-ocimene $e^{\text {f,g }}$ & & & & & & \\
\hline 12 & 1052 & 1264 & Cis- $\beta$-ocimene ${ }^{f, g}$ & Mint & 3.02 & 2.73 & - & - & - \\
\hline 13 & 1059 & 1241 & $\gamma$-Terpinene $\mathrm{f}^{\mathrm{f,g}}$ & $\mathrm{np}$ & - & - & - & - & - \\
\hline 14 & 1067 & - & Trans-sabinenehydrate ${ }^{\mathrm{f}, \mathrm{g}}$ & np & & & & & \\
\hline 15 & 1076 & 1565 & 1-Octanol ${ }^{\mathrm{e}, \mathrm{f}, \mathrm{g}}$ & Stink bug & - & - & 4.51 & - & - \\
\hline 16 & 1085 & & terpinolene (mixture) $)^{\mathrm{f}, \mathrm{g}}$ & & & & & & \\
\hline 17 & 1088 & 1275 & Terpinolene (mixture) $)^{\mathrm{f}, \mathrm{g}}$ & Eucalyptus & 4.55 & 2.97 & - & - & - \\
\hline 18 & 1098 & - & Cis-sabinenehydrate ${ }^{\mathrm{f}, \mathrm{g}}$ & Plastic & - & 2.40 & - & - & 2.60 \\
\hline 19 & 1105 & 1555 & Linalool $^{\mathrm{e}, \mathrm{f}, \mathrm{g}}$ & Lavender & 3.07 & 2.62 & 2.50 & 1.40 & 2.06 \\
\hline 20 & 1108 & 1401 & Nonanal ${ }^{\mathrm{f}, \mathrm{g}}$ & Green, fruity & 5.51 & 4.73 & 2.21 & - & - \\
\hline 21 & 1112 & 1382 & $\rho$-Mentha-1,3,8-triene $e^{\mathrm{f}, \mathrm{g}}$ & Citrus & - & - & 3.71 & - & - \\
\hline 22 & 1131 & 1682 & Ethyl 3-hydroxyhexanoate ${ }^{\text {f,g }}$ & np & - & - & - & - & - \\
\hline 23 & 1143 & 1367 & Allocimene $e^{\mathrm{f}, \mathrm{g}}$ & Sweety, citrus & 2.01 & 2.00 & - & - & - \\
\hline 24 & 1148 & - & ni & Green leaf & 1.71 & 2.45 & 4.20 & - & - \\
\hline 25 & 1177 & 1598 & Terpinen-4-ole,f,g & Grease & 1.39 & 1.79 & 4.68 & 1.68 & - \\
\hline 26 & 1190 & 1698 & $\alpha$-Terpineol ${ }^{\mathrm{e}, \mathrm{f}, \mathrm{g}}$ & Citrus & 2.76 & 4.29 & 3.91 & - & 3.53 \\
\hline 27 & 1196 & 1528 & Cis-4-decenal ${ }^{\mathrm{f}, \mathrm{g}}$ & Eucalyptus & 2.62 & 4.55 & - & 1.41 & 2.13 \\
\hline 28 & 1202 & 1435 & Ethyl octanoate $e^{\mathrm{f}, \mathrm{g}}$ & Citrus, eucalyptus & 5.14 & 2.05 & - & - & - \\
\hline 29 & 1209 & 1499 & Decanal $^{\mathrm{e}, \mathrm{f}, \mathrm{g}}$ & citrus & 5.24 & 6.61 & 2.64 & - & 3.12 \\
\hline 30 & 1217 & 1476 & Octylacetate $\mathrm{f}^{\mathrm{fg} g}$ & $\mathrm{np}$ & - & - & - & - & - \\
\hline 31 & 1219 & 1865 & Carveol $^{\mathrm{f}, \mathrm{g}}$ & np & - & - & - & - & - \\
\hline 32,33 & 1230 & $1804+1772$ & Nerol $^{\mathrm{f}, \mathrm{g}}+\beta$-citronellol ${ }^{\mathrm{e}, \mathrm{f}, \mathrm{g}}$ & $\mathrm{np}$ & 2.64 & 4.73 & 4.26 & - & 3.11 \\
\hline 34 & 1243 & 1722 & Carvone (mixture) $)^{\mathrm{f}, \mathrm{g}}$ & $\mathrm{np}$ & - & - & - & - & - \\
\hline 35 & 1257 & 1854 & Geraniolf,g & $\mathrm{np}$ & - & - & - & - & - \\
\hline 36 & 1259 & - & Linalylacetate $\mathrm{f}^{\mathrm{fg}}$ & Citrus & - & 2.39 & - & - & - \\
\hline
\end{tabular}


Table 1 (continued)

\begin{tabular}{|c|c|c|c|c|c|c|c|c|c|}
\hline \multirow{2}{*}{ Peak $^{\mathrm{a}}$} & \multirow{2}{*}{$\mathrm{RI}^{\mathrm{b}}$} & \multirow{2}{*}{$\mathrm{RI}^{\mathrm{c}}$} & \multirow{2}{*}{ Compound } & \multirow{2}{*}{ Aroma description } & \multicolumn{5}{|l|}{$\mathrm{GC}-\mathrm{O}^{\mathrm{d}}$} \\
\hline & & & & & Extraction & Finishing & $1^{\text {st }}$ stage evaporator & Concentration & Blending \\
\hline 37 & 1272 & 1768 & Perillaldehyde $e^{e, f, g}$ & Tea, citrus, eucalyptus & 3.00 & 3.00 & - & - & - \\
\hline 38 & 1276 & - & 1-Decanol ${ }^{\mathrm{f}, \mathrm{g}}$ & Ripen fruit & - & 1.55 & 2.20 & - & 3.13 \\
\hline 39 & 1290 & - & Carvacrol $^{\mathrm{f}, \mathrm{g}}$ & np & - & - & - & - & - \\
\hline 40 & 1298 & - & Perillaalcohol $^{\mathrm{f}, \mathrm{g}}$ & Citrus, eucalyptus & 2.24 & - & - & - & - \\
\hline 41 & 1309 & - & Undecanal $^{\text {ef,g }}$ & np & & - & - & - & - \\
\hline 42 & 1333 & - & ni & Stink bug & 4.35 & 4.53 & 2.53 & - & 1.22 \\
\hline 45 & 1357 & 1661 & Citronellylacetate $e^{\mathrm{f}, \mathrm{g}}$ & np & - & - & - & - & - \\
\hline 46 & 1368 & 1726 & Nerylacetate $^{\mathrm{f}, \mathrm{g}}$ & np & - & - & - & - & - \\
\hline 47 & 1373 & 1444 & $\alpha$-Copaene $e^{f, g}$ & np & - & - & - & - & - \\
\hline 48 & 1384 & 1468 & $\delta$-Elemene $e^{\text {f,g }}$ & np & - & - & - & - & - \\
\hline 49 & 1388 & 1757 & Geranylacetate $\mathrm{f}^{\mathrm{f}, \mathrm{g}}$ & np & - & - & - & - & - \\
\hline 50 & 1391 & 1687 & $\gamma$-Elemene $e^{f, g}$ & np & - & - & - & - & - \\
\hline 51 & 1400 & 1537 & Longifolene $e^{e, f, g}$ & citrus & 0.79 & 1.52 & - & - & - \\
\hline 52 & 1403 & 1400 & Tetradecane $e^{\mathrm{f}, \mathrm{g}}$ & np & - & - & - & - & - \\
\hline 53,54 & 1411 & $1707+1575$ & Dodecanal $^{\mathrm{f}, \mathrm{g}}+$ caryophyllene $^{\mathrm{f}, \mathrm{g}}$ & Sweety, citrus & 1.66 & 3.13 & - & - & - \\
\hline 55 & 1426 & 1611 & $\beta$-Copaene $e^{f, g}$ & $\mathrm{np}$ & - & - & - & - & - \\
\hline 56 & 1437 & 1851 & Perillylacetate $e^{\mathrm{f}, \mathrm{g}}$ & np & - & - & - & - & - \\
\hline 57 & 1448 & 1647 & Humulene $e^{f, g}$ & np & - & - & - & - & - \\
\hline 58 & 1471 & 1676 & Gurjunene $\mathrm{e}_{\mathrm{f}, \mathrm{g}}$ & $\mathrm{np}$ & - & - & - & - & - \\
\hline 60 & 1492 & 1698 & Valencene $e^{e, f, g}$ & np & - & - & - & - & - \\
\hline 61 & 1501 & 1715 & Eremophilene $\mathrm{f}^{\mathrm{fg}}$ & np & - & - & - & - & - \\
\hline 62 & 1514 & - & panasinsene $e^{f, g}$ & np & - & - & - & - & - \\
\hline 63 & 1523 & 1740 & $\delta$-Cadinene $e^{f, g}$ & np & - & - & - & - & - \\
\hline 64 & 1538 & - & Guaia-3,9-diene $e^{\mathrm{f}, \mathrm{g}}$ & np & - & - & - & - & - \\
\hline 65 & 1578 & 1964 & Caryophileneoxide $^{\mathrm{f}, \mathrm{g}}$ & np & - & - & - & - & - \\
\hline 66 & 1654 & - & Selina-3,7 (11)-diene $e^{\text {f,g }}$ & np & - & - & - & - & - \\
\hline 67 & 1800 & - & Nootkatone $e^{f, g}$ & $\mathrm{np}$ & - & - & - & - & - \\
\hline 68 & 2009 & - & Isopropyl palmitate ${ }^{\mathrm{f}, \mathrm{g}}$ & np & - & - & - & - & - \\
\hline
\end{tabular}

$\mathrm{ni}=$ compound non-identified;

$\mathrm{np}=$ not perceived by OSME.

a The odoriferous compounds were represented by the same numbers of the peaks on the chromatogram. Letters were attributed to those compounds that were only perceived by GC-O.

b Retention index in HP-5MS column from GC-FID and GC-MS.

c Retention index in DB-Wax column from GC-MS.

d GC-O: odoriferous intensity, 0.1 to 10.0 .

e Compound identified by pure standards' retention time.

f Compound identified by mass spectrometry.

g Compound identified by the retention index.

It should be noticed that changes in the volatile compounds profile and aroma are related to the heat applied in the $1^{\text {st }}$ stage of evaporator step, because a remarkable decrease in odour intensity occurred from the $1^{\text {st }}$ stage of evaporator step up to the blending step. A lot of compounds are lost, consequently reducing the natural and characteristic aroma of orange juice (Janzantti et al., 2011). In the blending step oil phase is currently added. D-Limonene, linalool, nerol and $\beta$-citronellol, $\alpha$-terpineol and decanal are typical compounds which increase odour intensity and area in the juice of the blending step. Although oil phase is added in the blending step, the final odour intensity and area of those volatile compounds were lower than the initial ones in the extraction and finishing steps, suggesting that the natural and characteristic aroma of freshly-squeezed orange juice is not replaced.

PCA was used to represent the data in two dimensions to differentiate the juice of each step of the FCOJ processing (Fig. 2). The first two principal components (PC) explained a variation of $80.53 \%$ of the aroma descriptors and odoriferous intensity in the juice of each step of the FCOJ processing. The PCA was suitable to differentiate the steps and group of descriptors according to their spatial location. The juice from the extraction and finishing steps, loaded negatively in PC1, showed higher intensities of the aroma descriptors sweety, citrus, eucalyptus, green leaf and mint. The juice from $1^{\text {st }}$ stage of evaporator step, loaded positively in PC1 and negatively in PC2, had higher intensities of the aroma descriptors ripen fruit, grease, plastic and stink bug. The juice from the concentration and blending steps, loaded positively in PC1 and PC2, had higher intensities of the aroma descriptors fatty and rotten. The aroma descriptors syrup, fruity, green, lavender, citrus and green leaf, loaded negatively in PC1 and PC2, were reduced during the processing, from the extraction and finishing steps up to the $1^{\text {st }}$ stage of evaporator step, while stink bug increased. The aroma descriptors gas and green leaf, loaded positively in PC1 and negatively in PC2, were more important to the aroma of the juice from the $1^{\text {st }}$ stage of evaporator, concentration and blending steps. The aroma descriptors eucalyptus and plastic, loaded negatively in PC1 and positively in PC2, were more important to the aroma of the juice from the extraction and finishing steps.

\subsection{Quantification of orange juice volatile compounds}

Table 2 shows the ten volatile compounds quantified in the orange juice from the steps of the FCOJ processing. Volatile compounds peak numbers in Table 2 correspond to those from Table 1.

Ethyl butanoate was higher in the juice from the finishing step, $2.03 \mu \mathrm{g} / \mathrm{mL}(p \leq 0.05)$, being strongly reduced in the $1^{\text {st }}$ stage of evaporator step, $3.11 \times 10^{-2} \mu \mathrm{g} / \mathrm{mL}(p \leq 0.05)$, as verified by OSME. $\beta$-pinene was higher in the juice from the extraction step $\left(2.33 \times 10^{-1} \mu \mathrm{g} / \mathrm{mL}\right)$, significantly differing from the finishing step $\left(7.13 \times 10^{-2} \mu \mathrm{g} / \mathrm{mL}\right)(p \leq 0.05)$. $\beta$-Myrcene showed similar behaviour as $\beta$-pinene, with $3.16 \mu \mathrm{g} / \mathrm{mL}$ in the juice from the extraction step and $1.30 \mu \mathrm{g} / \mathrm{mL}$ in the finishing step ( $p \leq$ 0.05 ). The level of $\beta$-pinene and $\beta$-myrcene in orange juice is related to the peel oil content of orange juice. Ahmed, Dennison, Dougherty, and Shaw (1978) suggested that $\beta$-myrcene makes a negative contribution to orange aroma in processed orange juice, while $\beta$-pinene is thought to make a positive contribution to orange aroma.

The two monoterpenes linalool and $\alpha$-terpineol, as well as the alcohol 1-octanol were quantified in the juice from all the FCOJ processing steps. Regarding 1-octanol, it was present in higher amounts in the finishing step ( $3.38 \mu \mathrm{g} / \mathrm{mL})$, followed by the extraction step $(p \leq 0.05)$, with no difference $(p>0.05)$ among the other steps. Linalool was higher in the juice from the finishing step $(0.10 \mu \mathrm{g} / \mathrm{mL})$, differing from all the 

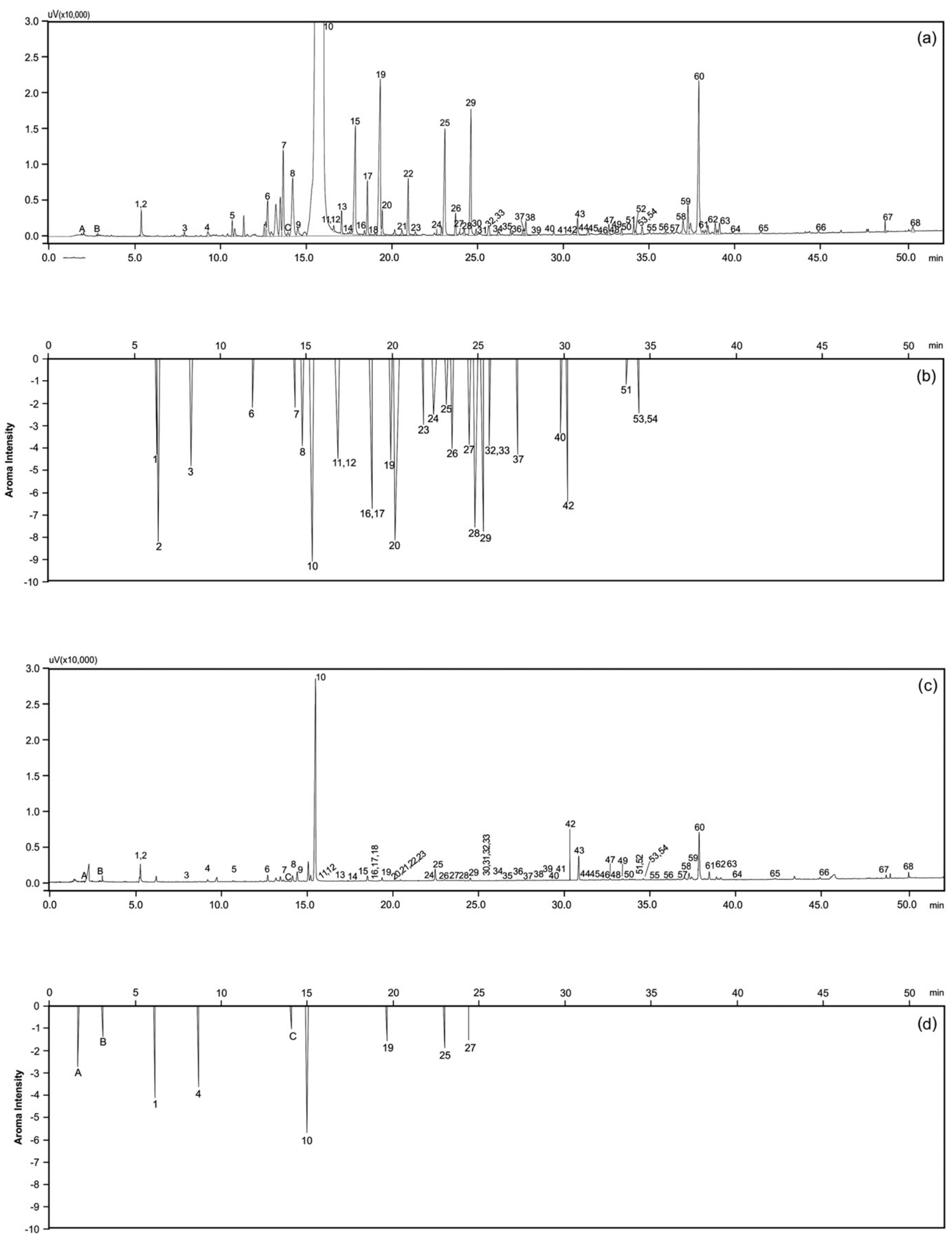

Fig. 1. Chromatogram and aromagram of orange juice from the extraction step (a, b) and from the concentration step (c, d). 

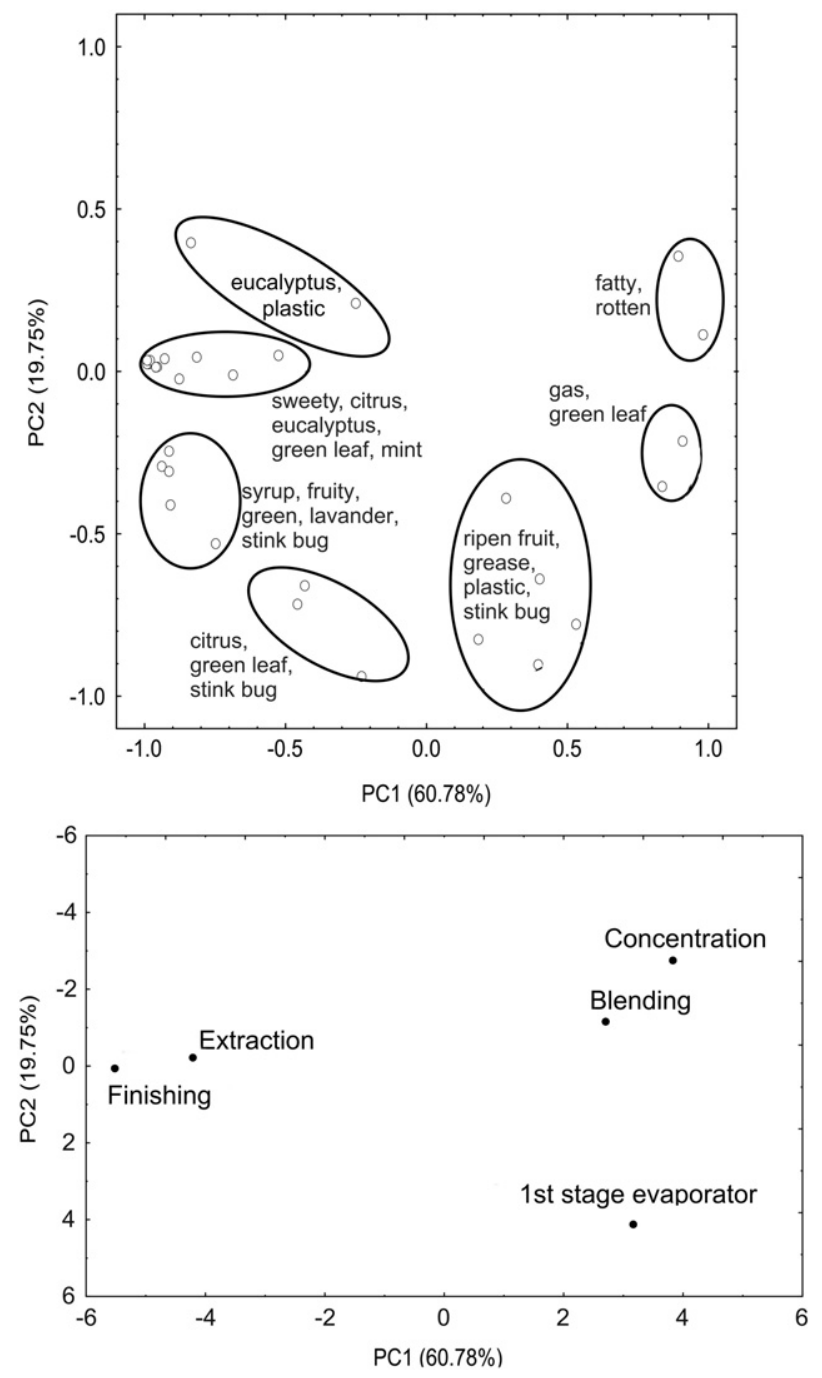

Fig. 2. PCA of the aroma of the orange juice from the FCOJ processing steps and volatile compounds odoriferous intensity.

other steps $(p \leq 0.05)$. No difference was found in linalool between $1^{\text {st }}$ stage of evaporator and concentration. The terpene $\alpha$-terpineol was higher in the juice from the finishing step $(0.13 \mu \mathrm{g} / \mathrm{mL})(p \leq 0.05)$. Jordán et al. (2003) reported that $\alpha$-terpineol is an indicator of the age of orange juice, that is derived from chemical degradation of limonene, which might be induced by heating. Levels higher than $2 \mu \mathrm{g} /$ $\mathrm{g}$ of $\alpha$-terpineol may adversely affect the juice flavour. $\beta$-Citronellol $\left(2.09 \times 10^{-1} \mu \mathrm{g} / \mathrm{mL}\right)$, perillaldehyde $\left(2.11 \times 10^{-2} \mu \mathrm{g} / \mathrm{mL}\right)$, and decanal $(9.45 \mu \mathrm{g} / \mathrm{mL})$ were higher in the juice from the finishing step $(p \leq 0.05)$. Longifolene was higher in the juice from the extraction step $\left(4.03 \times 10^{-3} \mu \mathrm{g} / \mathrm{mL}\right)$, followed by the finishing $\left(2.95 \times 10^{-3} \mu \mathrm{g} / \mathrm{mL}\right)$, $1^{\text {st }}$ stage of evaporator $\left(2.84 \times 10^{-3} \mu \mathrm{g} / \mathrm{mL}\right)$ and blending steps $\left(2.79 \times 10^{-3} \mu \mathrm{g} / \mathrm{mL}\right)(p \leq 0.05)$. Longifolene was not found in the concentration step, suggesting it was replaced in the blending step (Table 2). All the compounds showed a decrease in concentration from the extraction and finishing step up to the end of the FCOJ processing, with statistically significant differences. Ethyl butanoate, $\beta$-pinene, $\beta$-myrcene, 1 octanol, linalool, $\alpha$-terpineol, decanal, $\beta$-citronellol, perillaldehyde and longifolene are odour-active, hence considered to be important contributors to the aroma of orange juice. A decrease in the concentration of these compounds represents an important loss for the orange juice aroma (Arena et al., 2006; Mastello et al., 2015; Rouseff et al., 2001). The concentration of the volatile compounds during processing corroborates the results obtained by GC-OSME. There is no information in literature over volatile compounds quantification in orange juice from the FCOJ processing steps. Baxter, Easton, Schneebeli, and Whitfield (2005) reported the relative concentration $(\mu \mathrm{g} / \mathrm{mL})$ of volatile compounds using HS-SPME in Navel orange juices that were untreated, temperature treated (pasteurised) and high pressure processed stored over a period of twelve weeks under refrigeration $\left(4^{\circ} \mathrm{C}\right)$ and temperature-abuse $\left(10^{\circ} \mathrm{C}\right)$, showing that in the unprocessed and temperature treated orange juice the volatile compounds laid within the same ranges found in the present study. The majority of compounds showed a decrease in concentration in the temperature treated when compared to the untreated juice similarly to our results. It is worth mentioning that Baxter et al. (2005) did not report statistical differences between the relative concentrations of volatile compounds of the juices, neither results of GC-O analysis, which would be a better way of comparison.

Selli and Kelebek (2011) also reported the level ( $\mu \mathrm{g} / \mathrm{L}$ ) of volatile compounds of blood orange juices from Moro and Sanguinello varieties, extracted by liquid extraction. They observed some differences in concentration values between varieties, but the volatile profile was quite similar. The concentrations of ethyl butanoate, $\beta$-myrcene, 1 -octanol, linalool, decanal reported in the juice from extraction step of the present study were higher than in orange juice from Moro and Sanguinello varieties. Hence there are differences between those and the Pêra-Rio orange juices of the present study. Ren et al. (2015) analysed juice from different citrus varieties by HS-SPME, with the same fibre used in the present study. They observed differences in sensory analysis and volatile compounds profile between varieties. Regarding orange juice, Hamlin variety was studied. The concentrations $(\mu \mathrm{g} / \mathrm{L})$ of ethyl butanoate, $\beta$-myrcene, $\alpha$-terpineol and decanal were higher in Hamlin orange juice when compared to those from extraction and finishing steps of Pêra-Rio orange juice. On the other hand, the concentrations of 1-octanol and linalool were lower in Hamlin orange juice. Although the volatile compounds levels reported by Selli and Kelebek (2011) and Ren et al. (2015) are in the same range of those reported in the present study, comparison of orange juices samples is not always suitable because of differences in variety, local of production, and processing conditions, among other factors.

In the present work the effectiveness of a combination of HS-SPMEGC-MS with GC-OSME and multivariate data analysis was demonstrated. Changes in the aroma and levels of volatile compounds during the FCOJ processing were also showed. The majority of compounds showed a decrease in odour intensity during the processing. PCA showed that syrup, fruity, green, lavender, citrus and green leaf descriptors were reduced during the processing, from the extraction and finishing steps up to the $1^{\text {st }}$ stage of evaporator step, while stink bug increased. Gas and green leaf descriptors were more important to the aroma of the juice from the $1^{\text {st }}$ stage of evaporator, concentration and blending steps, and eucalyptus and plastic to the juice from the extraction and finishing steps. For the first time it was possible to establish which volatile compounds and aroma descriptors characterise the juice from each step of the FCOJ processing. Our results showed that in the $1^{\text {st }}$ stage of evaporator step the majority of compounds are lost, affecting the final product aroma quality. Ethyl butanoate was higher in the juice from the finishing step, being strongly reduced in the $1^{\text {st }}$ stage of evaporator step, and $\beta$-pinene, myrcene and longifolene were higher in the juice from the extraction step. 1-octanol, linalool, $\alpha$-terpineol, $\beta$-citronellol, perillaldehyde and decanal were higher in the finishing step. The oil phase addition in the blending step could not recover odour intensity, area and levels of the volatile compounds.

Even though FCOJ processing has been applied for a long time there is no information concerning the identification and quantification of volatile compounds at each processing step and their impact on the aroma and flavour of the juice. The study of the processing steps enriches the current industrial knowledge indicating which steps there are substantial losses of aroma that affect orange juice quality. Our results can support the industry on controlling the processing conditions in order 


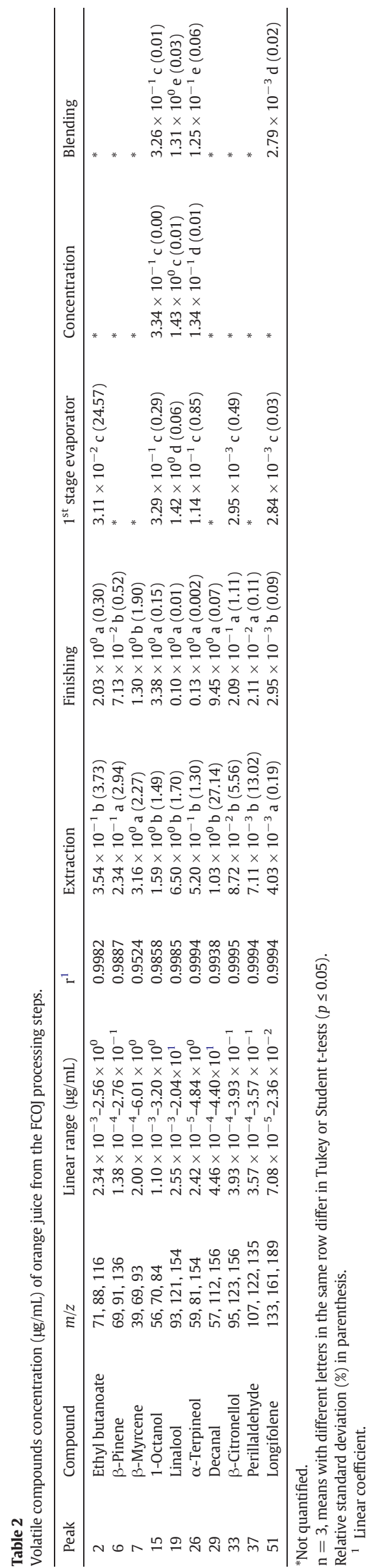

to avoid and/or minimise the loss of important compounds responsible for the characteristic, natural and fresh orange juice aroma.

\section{Acknowledgements}

This research was supported by São Paulo Research Foundation (FAPESP) - grant 2009/15084-0, CNPq (Process 483785/2010-5) and PADC/FCF/UNESP - grant 2013/14-1.

\section{References}

Acree, T., \& Arn, H. (2015). Flavornet. August 20. Available at http://www.flavornet. org/flavornet.html.

ASTM - American Society for Testing and Material (1981). Guidelines for the selection and training of sensory panel members. Philadelphia: ASTM.

Ahmed, E. M., Dennison, R. A., Dougherty, R. H., \& Shaw, P. E. (1978). Flavor and odor thresholds in water of selected orange juice components. Journal of Agricultural and Food Chemistry, 26(1), 187-191.

Arena, E., Guarrera, N., Campisi, S., \& Nicolosiasmundo, C. (2006). Comparison of odour active compounds detected by gas-chromatography-olfactometry between hand-squeezed juices from different orange varieties. Food Chemistry, 98(1), 59-63.

Baxter, I. A., Easton, K., Schneebeli, K., \& Whitfield, F. B. (2005). High pressure processing of Australian navel orange juices: Sensory analysis and volatile flavor profiling. Innovative Food Science E' Emerging Technologies, 6, 372-387.

Brunschwig, C., Senger-Emonnot, P., Aubanel, M. -L., Pierrat, A., George, G., Rochard, S., et al. (2012). Odor-active compounds of Tahitian vanilla flavor. Food Research International, $46,148-157$.

Da Silva, M. A. A. P., Lundhal, D. S., \& McDaniel, M. R. (1994). The capability and psychophysics of OSME: A new GC-olfactometry technique. In H. Maarse, \& D. G. Van Der Heij (Eds.) Trends in flavour research (pp. 191-209). Amsterdam: Elsevier.

Elston, A., Sims, C., Mahattanatawee, K., \& Rouseff, R. (2006). Determination of commercia orange juice quality factors using descriptive and GCO analyses. Flavour Science: Recent Advances and Trends, 46, 541-544.

Janzantti, N. S., Machado, T. V., \& Monteiro, M. (2011). Sensory acceptance of juice from FCOJ processing steps. Journal of Sensory Studies, 26(5), 322-330.

Janzantti, N. S., Macoris, M. S., Garruti, D. S., \& Monteiro, M. (2012). Influence of the cultivation system in the aroma of the volatile compounds and total antioxidant activity of passion fruit. Lebensmittel-Wissenschaft und Technologie, 46, 511-518.

Jordán, M. J., Goodner, K. L., \& Laencina, J. (2003). Deaeration and pasteurization effects on the orange juice aromatic fraction. Lebensmittel-Wissenschaft und Technologie, 36(4), 391-396.

Kebede, B. T., Grauwet, T, Tabilo-Munizaga, G, Palmers, S, Cervoort L, Hendrickx, M, et al. (2013). Headspace components that discriminate between thermal and high pressure high temperature treated green vegetables: Identification and linkage to possible process-induced chemical changes. Food Chemistry, 141, 1603-1613.

Mastello, R. B., Capobiango, M., Chin, S., Monteiro, M., \& Marriott, P. (2015). Identification of odour-active compounds os pasteurised orange juice using multidimensional gas chromatography techniques. Food Research International, 75, 281-288.

Nagy, S., \& Chen, C. S. (1993). Orange and tangerine juices. In P. E. Shaw (Ed.), Fruit juice processing technology (pp. 111-135). Auburndale, FL: Agscience, Inc.

Obenland, D., Collin, S., Sievert, J., Fjeld, K., Doctor, J., \& Arpaia, M. L. (2008). Commercia packing and storage of navel oranges alters aroma volatiles and reduces flavor quality. Postharvest Biology and Technology, 47(2), 159-167.

Perez-Cacho, P. R., \& Rouseff, R. L. (2008). Fresh squeezed orange juice odor: A review Critical Reviews in Food Science and Nutrition, 48(7), 681-695.

Ren, J. -N., Tai, Y. -N., Dong, M., Shao, J. -H., Yang, S. -Z., Pan, S. -Y., \& Fan, G. (2015) Characterisation of free and bound volatile compounds from six different varieties of citrus fruits. Food Chemistry, 185, 25-32.

Rouseff, R., Bazemore, R., Goodner, K., \& Naim, M. (2001). GC-Olfactometry with solid phase microextraction of aroma volatiles from heated and unheated orange juice. In R. A. Cadwallader (Ed.), Headspace analysis of food and flavors: Theory and practice (pp. 101-112). New York: Kluwer Academic/Plenum Publishers.

Selli, S., \& Kelebek, H. (2011). Aromatic profile and odour-activity value of blood orange juices obtained from Moro and Sangunello (Citrus Sinensis L. Osbeck). Industrial Crops and Products, 33, 727-733.

Shaw, P. E. (1991). Fruit juice. In R. E. Kirk, D. F. Othmer, J. I. Kroschwitz, \& M. Howe-Grant (Eds.), Encyclopedia of chemical technology (pp. 1082-1097). New York: Wiley.

Shaw, P. E., Buslig, B. S., \& Moshonas, M. G. (1993). Classification of commercial orange juice types by pattern recognition involving volatile constituents quantified by gas chromatography. Journal of Agricultural and Food Chemistry, 41, 809-813.

Steffen, A., \& Pawliszyn, J. (1996). Analysis of flavor volatiles using headspace solid-phase microextraction. Journal of Agricultural and Food Chemistry, 44(8), 2187-2193.

Tønder, D., Petersen, M. A., Poll, L., \& Olsen, C. E. (1998). Discrimination between freshly made and stored reconstituted orange juice using GC odour profiling and aroma values. Food Chemistry, 61, 223-229.

van Den Dool, H., \& Kratz, P. (1963). A generalization of the retention index system including linear temperature programmed gas-liquid partition chromatography. Journal of Chromatography A, 11, 463-471.

Vervoort, L., Grauwet, T., Kebede, B. T., Van der Plancken, I., Timmermans, R., Hendrickx, M., et al. (2012). Headspace fingerprinting as an untargeted approach to compare nove and traditional processing technologies: a case-study on orange juice pasteurisation. Food Chemistry, 134(4), 2303-2312. 